\title{
Old women's self perceptions of dependency and some implications for service provision
}

\author{
HELEN EVERS \\ From the Department of Sociology, University of Warwick
}

SUMMARY Fifty women aged 75 years or older who were living alone were visited to determine their self perception of dependency. There was a wide variety in reported capacity for self care but two patterns are isolated: those who were active initiators with a self perception of independence and passive responders with a perception of dependence. Service providers should take cognisance of the woman's self perception in the effective delivery of services.

Health and the consequences of ill health and dependency are intimately linked with social, economic, and environmental factors, not least for old people. Official statistics and reports ${ }^{12}$ provide information about levels of formal service provision to the elderly population. Research studies ${ }^{3}$ add to our knowledge of levels and patterns of community service delivery to various categories of old people. Relatively little is known about those who do not come to the attention of formal services, although population surveys ${ }^{4-6}$ indicate among other things that the relation between dependency or health status and provision of support is by no means a simple one. Other research shows that the "problems" of old people and their family carers seldom fit neatly into service-defined categories, ${ }^{7}$ and that multiple and often conflicting interests may be at work when concrete decisions have to be made about how "best" to provide support. ${ }^{8}$

Our knowledge of how ordinary old people perceive their circumstances, organise their lives, and cope with any ill health they may suffer is particularly scanty. Yet in 1948 Sheldon $^{9}$ recognised the importance of considering these factors as a prerequisite to developing health and social care services for old people. His survey, which succeeded in effecting a balance between the wide coverage possible through the use of survey methods and in-depth analysis of respondents' own perceptions, remains a classic one.

In this paper I examine how old women view their daily lives and any supportive relationships to which they may be party.

\section{Research questions and methods}

Three major questions underlie the research.

1 Given that formal services are often provided in a serendipitous fashion and that "need" has as many different definitions as there are interested parties, what are the key personal and social factors and processes that shape support relationships?

2 Given that informal carers do most of the work, could services help rather more systematically and successfully than the literature ${ }^{71011}$ would have us believe? As a practical question this is particularly important in the current climate of economic austerity.

3 Given that a majority of the elderly population is female, how do old women perceive their strengths and problems, and how do they evaluate any support relationships in which they are engaged? ${ }^{12}$

Such broad and open-ended research questions as these, focussing primarily on old people's own definitions of their situations, can best be explored through qualitative methods in the first instance. Thus the research group consists of 50 women aged 75 years or more who live alone. Household composition bears some relation to both functional capacity and provision of support. ${ }^{46}$

In a small-scale study, where this variable is not the main focus, the easiest solution is to control for household composition. Women living alone comprise a substantial proportion of the oldest section of the population: $23 \%$ of men and $48 \%$ of women over 75 live alone. ${ }^{16}$ The study women were selected at random from the age/sex registers of two 
group general practices located in different residential areas of Birmingham, England, a city of some 1 million population. Open-ended interviews seek women's views on their housing; biographical details including aspects of life history; day-to-day life, including pleasures, problems, and future prospects; perceptions of health, history of ill-health, if any, and how it affects daily life; contacts and/or helping relationships with kin, friends, and neighbours; contacts with formal and voluntary services; and financial circumstances. If the women are receiving support which they regard as important, the main supporters are contacted, provided the women agree to this, and asked about their perceptions of the support relationship. About six months later the women and their supporters are again interviewed, with particular reference to any changes that have taken place in the interim, whether in health, housing arrangements, or social or support networks, and how any key decisions about support arrangements were made. By the beginning of 1984 all first interviews and 30 second interviews had been carried out. A complete data analysis is not, therefore, to hand. Thus I will discuss just one emergent topic: women's perceptions of dependency. This is relevant to health service providers, as will be shown below.

\section{'Research subjects}

Their ages range from 75 to 96 , the average age being just over 80 years. Four had never married and eight had no living children. All the women had been living alone for several years. Eleven were owner occupiers, and one was a car owner. The old age pension and in many cases supplementary pension were the major sources of income for the majority. Most had been married to men who were manual workers, and many had themselves worked during some, if not all, of their married lives, the commonest occupations being factory, office, domestic or shop work. A majority had left school by the age of 14 or earlier, usually without any formal qualifications.

\section{Perceptions of dependency}

The General Household Survey for $1980^{6}$-one of the most recent population studies paying particular attention to elderly people-shows that more than $50 \%$ of women aged 75 or over report that they suffer from some chronic condition which limits their activities. This survey also contains data on reported capacity for self care. For women over 75 who live alone, as many as $23 \%$ are usually unable to go out and walk down the road alone; $15 \%$ cannot manage stairs alone. Cutting toenails is impossible for $46 \%$, as also is bathing for $12 \%$. A substantial proportion cannot manage a range of routine domestic tasks alone, for example, $28 \%$ are unable to do their own shopping and $21 \%$ cannot cook a meal.

Among the $\mathbf{5 0}$ women of my research group, there was a great variety in reported capacity for self-care. At one extreme, respondents were entirely independent and were also providing help of various kinds for other people; at the other, two women said they could do almost nothing for themselves.

Their health and physical capacity for leading autonomous and independent lives did not, however, bear a straightforward relation with the women's perceptions of the extent to which they were actually "in charge" of their own lives, as opposed to dependent on others to organise things for them. At this stage of the research two broad categories emerge. Women who can be described as active initiators see themselves as being in control of their own lives despite in some cases very considerable reliance on others for help with the basic activities of daily life. Women who can be described as passive responders see themselves as being largely dependent on others to organise and structure their lives for them, despite in some cases apparently having the capacity for relatively autonomous living. Two examples will illustrate this.

\section{MRS AB (ACTIVE INITIATOR)}

This 89-year-old woman appeared very frail and reported that she suffered various health problems including poor eyesight, poor hearing, arthritis, and recurrent chest complaints. She had six living children, all of whom lived near enough to visit regularly and to provide some practical help. One of her daughters was the mainstay, calling on her mother each day and helping with numerous tasks around the house and garden. Mrs AB maintained her independent status in various ways: she insisted on cooking a meal for her daughter each day, although she had been urged to accept meals on wheels. She also insisted on contributing to the "housekeeping" each week when she stayed with any of her children, as sometimes she did. When I interviewed her, she had recently organised a large family party at a local restaurant to celebrate her 89 th birthday as a surprise for her many relations. Mrs AB clearly enjoyed life, did not see herself as dependent, and felt in control of her circumstances despite her problems.

\section{MRS CD (PASSIVE RESPONDER)}

In contrast, Mrs $C D$, who was 87 years old, relied entirely on other people to organise her life. She suffered from deafness and arthritis and had a history of falls, although she had not fallen for almost a year when I first interviewed her. She was incontinent of 
urine. She seemed content to sit in front of her fire, watching television or reading a book and waiting for her next helper to arrive. She was receiving meals on wheels on weekdays, home help seven days a week, a visit from the bath attendant once a week, special laundry service, and a weekly visit from her only daughter, who did the shopping, paid the bills, and took care of the washing other than bed linen. Mrs CD's door was always ajar, and any new arrival was expected to make her a cup of tea.

The consensus among Mrs CD's helpers-who had been mobilised by a hospital consultant during one of her hospital admissions-was that, although she suffered real difficulties with mobility, she was capable of doing far more for herself. All were agreed that much of the urinary incontinence seemed to be due to her reluctance to walk to the toilet; she had been in hospital several times following falls, and on each occasion toilet training regimes had proved successful while she remained in hospital and was made to walk to the toilet. Mrs CD saw herself as highly dependent and seemed to accept her circumstances cheerfully.

Cases such as these two women exemplify are, of course, commonplace. One approach to accounting for the differences between these types has recourse to notions of personality differences and of "successful adjustment" to ageing and any contingent problems. For example, the case of Mrs $\mathrm{AB}$ brings to mind the tenets of "activity theory,"17 which holds that successful adjustment to old age features active social participation. Mrs CD exemplifies the views of "disengagement theory": ${ }^{18}$ that gradual withdrawal from social roles characterises "successful" ageing. What is emerging from this research, however, is a different kind of explanation, deriving from social factors and having some practical implications for service delivery.

$\bar{P}$ assive responders tend to have engaged for much of their lives in home-based, unpaid work of caring for family members. Although several of them had had paid work outside the home, they did not seem to have gained much intrinsic satisfaction from their work: it had been largely menial, a means of gaining essential additional income for the family which had remained their overriding concern. Hobbies and interests had often been sacrificed for the sake of family duties. Now, in late life, bereft of their active caring roles, these women seemed to have lost their sense of purpose. The daughter of Mrs CD, her only child, considered that her mother had had a hard life. She had not had paid work after her marriage and had cared for her sick husband for many years before his death. She had remarried late in life, and after one year of great happiness her second husband had suffered a heart attack. Although suffering considerably from arthritis, she had nursed her sick husband for the remaining three years of his life. The daughter said, "It was as though she had made herself keep going for him. When he died, she just sat down in her chair and expected to be looked after, and she has remained thus ever since," (a period of some five years) "it was odd, really quite astonishing, she became a different person."

In contrast, active initiators tended to have been able throughout their lives to invest energy into activities over and above their involvement in traditional "women's work" in the home. They were more likely to have been employed outside the home, in work which they found intrinsically or socially rewarding as well as financially necessary. They were also more likely to have had hobbies or interests they had pursued over many years, alongside their home-based and paid work commitments. Mrs AB, for example, had been the lynchpin of the family grocery shop which, alongside caring for her large family, she had found hard but rewarding.

\section{Discussion}

If women's life histories are important in shaping their perceptions of their own dependency-activity or passivity-this may have implications for service provision. Service providers may often first encounter an old woman when she is "not herself"; she may be ill or have suffered a bereavement, for example. If a woman's usual self-perception of relative activity or passivity is not discovered, intervention may prove less than appropriate. An active initiator could be treated as though she were passive, an object rather than subject of service provision. Not only might this be a painful denial of the woman's adult status, there is always the danger of her subjugation into passivity. Thus service provision that does not take cognisance of her usual self is in danger of escalating demand for service. And the parallel case can be stated for passive responder women: overzealous intervention may prove both unintentionally cruel, and frustrating for service providers who fail to achieve their own rehabilitative or curative goals. Service providers may be better able to strike the right balance between the inhumane extremes of reinforcing dependence on the one hand, and enforcing unwelcome independence on the other, when they know something of the women's usual self perceptions. This is particularly important, given that the woman's self perceptions-classified simply as active initiator or passive responder here-do not seem entirely congruent with the usual notions of dependency applied by health professionals and other formal service providers. Only a qualitative study could have revealed this. 
Prematurely conducted surveys may be in danger of inappropriately applying pre-existing categories to research populations.

These preliminary findings, based on qualitative research methods, about elderly women's perceptions of themselves, their circumstances, and support relationships should have practical implications for the way service providers assess needs, respond to them, and assess outcomes. Discovering and acting upon the patient's perspective is of the essence in service provision. Regular contacts between primary health care providers and patients, for example through screening clinics or regular home visits, could facilitate this. Such an investment of time and energy could pay dividends when serious health problems arise. These data will be subjected to further analysis, and subsequently larger scale surveys could seek to establish how the factors discussed here might manifest themselves in representative samples of elderly populations. Comparative studies of women and men are also needed.

This paper derives from research funded by The Nuffield Foundation.

\section{References}

${ }^{1}$ DHSS. Health and Personal Social Services Statistics; 11 ; 1982; London: Government Statistics Service, 1983.

${ }^{2}$ DHSS. On the state of the Public Health for the year 1982, London: HMSO, 1983.

${ }^{3}$ Fennell G, ed. DHSS seminar on support for elderly people living in the community: Synopses of research funded by DHSS, DOE and other agencies. London: DHSS, 1982.

${ }^{4}$ Hunt A. The elderly at home. A study of people aged sixty five and over living in the community in England in 1976. London: HMSO, 1978.
${ }^{5}$ Bond J, Carstairs V. Services for the elderly Scottish Health Service Studies No. 42, Edinburgh: Scottish Home and Health Department, 1982.

${ }^{6}$ Office of Population Censuses and Surveys, Social Survey Division, General household survey 1980 No. 10 London: HMSO, 1982.

${ }^{7}$ Rossiter C, Wicks M. Crisis or challenge? Family care, elderly people and social policy. London: Study Commission on the Family, 1982.

${ }^{8}$ Fairhurst E. Teamwork as panacea: Some underlying assumptions. Unpublished paper read at Annual Conference of the Medical Sociology Group, British Sociological Association. University of Warwick: 1977.

${ }^{9}$ Sheldon J. The social medicine of old age. Oxford: Oxford University Press for the Nuffield Foundation, 1948.

${ }^{10}$ Equal Opportunities Commission. Caring for the elderly and handicapped: Community care policies and women's lives. Manchester: Equal Opportunities Commission, 1982.

${ }^{11}$ Nissel M, Bonnerjea L. Family care of the handicapped elderly: Who pays? London: Policy Studies Institute, 1982.

${ }^{12}$ Sheldon ${ }^{9}$ found that the health status of old men and old women differed in systematic ways; demographic data and statistical evidence ${ }^{613}$ suggests that the life chances and circumstances of old men and women differ across social classes and income groups, yet service providers and policy makers have largely treated gender as a factor of no great significance in service planning and delivery. I have discussed some of the issues elsewhere. ${ }^{14} 15$

${ }^{13}$ Abrams M. Beyond three-score and ten. A second report on a survey of the elderly. Mitcham: Age Concern, 1980.

${ }^{14}$ Evers H. Elderly women and disadvantage: Perceptions of daily life and support relationships. In: Jerrome D, ed. Ageing in modern society. London: Croom Helm, 1983.

${ }^{15}$ Evers $\mathrm{H}$. The frail elderly woman: Emergent questions in aging and women's health. In: Lewin E, Olesen V, eds. Women, health and healing: Towards a new perspective. London: Tavistock, forthcoming.

${ }^{16}$ Central Statistical Office, Social trends 1984 No. 14 London: HMSO, 1983.

${ }^{17}$ Lemon BW, Bengtson VL, Petersen JA. An exploration of the activity theory of aging: Activity types and life expectation amongst in-movers to a retirement community. J Gerontology 1972; 27: 511-23.

${ }^{18}$ Cumming E, Henry W. Growing old. New York: Basic Books, 1961. 